SCOTTÁ, B.A. et al. Valina, isoleucina e leucina para aves. PUBVET, Londrina, V. 8, N. 1, Ed. 250, Art. 1652, Janeiro, 2014.

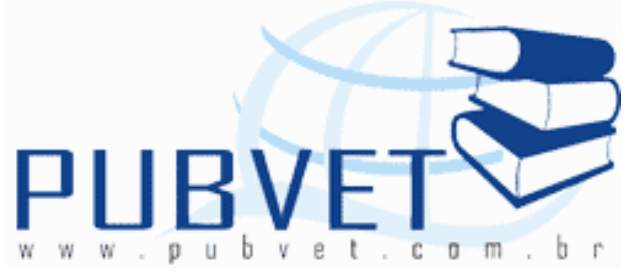

PUBVET, Publicações em Medicina Veterinária e Zootecnia.

\title{
Valina, isoleucina e leucina para aves
}

\author{
Bruno Andreatta Scottá ${ }^{1}$, Priscila Furtado Campos $^{1}$, Ana Paula Cardoso \\ Gomide $^{1}$, Carlota Coelho Barroca ${ }^{1}$, Andressa da Silva Formigoni ${ }^{2}$, Bárbara \\ Lopes de Oliveira ${ }^{3}$
}

${ }^{1}$ Doutorando (a) do Programa de Pós-Graduação em Zootecnia da Universidade Federal de Viçosa - UFV.

${ }^{2}$ Doutoranda do Programa de Pós-Graduação em Zootecnia da Universidade Federal de Minas Gerais - UFMG.

3Estudante de Graduação em Zootecnia da Universidade Federal de Viçosa UFV.

\section{Resumo}

Esta revisão teve como objetivo demonstrar a importância da valina, isoleucina e leucina na nutrição de aves, destacando o metabolismo desses aminoácidos, suas funções e exigências para frangos de corte e poedeiras. Quando se trabalha com o conceito da proteína ideal e com níveis de proteína bruta reduzidos nas rações, a adição de aminoácidos industriais é essencial, para que os animais recebam o aporte ideal de aminoácidos essenciais e não essenciais. A valina, isoleucina e leucina são aminoácidos essenciais para as aves em todas as fazes de criação, em dietas a base de milho e farelo de soja e com baixo nível de proteína bruta a valina é considerada o quarto aminoácido limitante e a isoleucina o quinto. Já a leucina dificilmente precisa ser 
SCOTTÁ, B.A. et al. Valina, isoleucina e leucina para aves. PUBVET, Londrina, V. 8, N. 1, Ed. 250, Art. 1652, Janeiro, 2014.

adicionada às dietas, pois é encontrada em grande quantidade nos alimentos normalmente usados nas formulações. Além da importância de definir as exigências nutricionais desses aminoácidos é necessário definir suas relações com a lisina, evitando assim excesso de aminoácidos e um possível antagonismo entre eles.

Palavras-chave: aminoácidos alifáticos, nutrição animal, proteína ideal

\title{
Valine, isoleucine and leucine for poultry
}

\begin{abstract}
This review aimed likely to demonstrate the importance of valine, isoleucine and leucine in poultry nutrition, highlighting the metabolism of these amino acids, their functions and requirements for broilers and laying hens. When working with the concept of ideal protein and reduced levels of crude protein in the diet, the addition of industrial amino acids is essential for animals to receive the optimal intake of essential and non-essential amino acids. The valine, isoleucine and leucine are essential amino acids for birds in all stages of creation, in diets based on corn and soybean meal and low protein levels, valine is considered the fourth limiting amino acid and isoleucine the fifth. Already leucine hardly needs to be added to the diets, as it is found in large quantities in foods commonly used in the formulations. Besides the importance of defining the nutritional requirements of these amino acids, is necessary to define its relations with lysine, avoiding excess amino acids and a possible antagonism between them.
\end{abstract}

Keywords: aliphatic amino acids, ideal protein, animal nutrition

\section{1 - Introdução}

A avicultura brasileira constitui uma importante atividade econômica, sendo constante a busca por alternativas para aumentar a produtividade e reduzir os custos de produção. 
SCOTTÁ, B.A. et al. Valina, isoleucina e leucina para aves. PUBVET, Londrina, V. 8, N. 1, Ed. 250, Art. 1652, Janeiro, 2014.

Do custo total de produção na avicultura, cerca de $70 \%$ tem sido atribuído à alimentação, sendo que os alimentos protéicos são responsáveis pela maior parte desse custo. Além do alto custo das fontes protéicas utilizadas na alimentação das aves, existe a preocupação com a poluição ambiental por nitrogênio, o que levou ao desenvolvimento de pesquisas que visam o atendimento adequado das exigências nutricionais das aves, evitando assim excesso de nutrientes.

Durante muitos anos, as formulações de rações para aves foram baseadas no conceito de proteína bruta, o que resultou em dietas com conteúdo de aminoácidos acima do exigido pelos animais. Com o início da produção de aminoácidos sintéticos, as dietas passaram a ser formuladas com menor nível protéico e com níveis de aminoácidos mais próximos das reais necessidades das aves. Entretanto, a redução excessiva da proteína da ração pode levar a deficiência dos aminoácidos não essenciais.

Segundo Emmert \& Baker (1997) a proteína ideal pode ser definida como o balanceamento exato dos aminoácidos, sem deficiências ou excessos, com o objetivo de satisfazer os requisitos absolutos de todos os aminoácidos para mantença e para ganho máximo de proteína corporal, reduzindo o uso de aminoácidos como fonte de energia e diminuindo a excreção de nitrogênio.

De acordo com Baker \& Han (1994), em situações práticas, os aminoácidos sulfurados, lisina, treonina, arginina, isoleucina, valina e triptofano são os aminoácidos de maior importância para a produção de aves. Apesar de grandes progressos na nutrição de aves, ainda não se tem pleno domínio sobre as relações aminoácidos essenciais/lisina. Visto que as exigências dos aminoácidos são diferentes, a relação entre eles será afetada pela idade das aves, sendo necessário determinar as relações dos aminoácidos essenciais/lisina para todas as fases de criação.

A valina, leucina e isoleucina são considerados aminoácidos alifáticos, bem similares em relação à função e estrutura. Estes aminoácidos são muito hidrofóbicos e se encontram quase sempre no interior das proteínas. Suas principais fontes são o farelo de soja, pescados e carnes (Duarte, 2009). 
SCOTTÁ, B.A. et al. Valina, isoleucina e leucina para aves. PUBVET, Londrina, V. 8, N. 1, Ed. 250, Art. 1652, Janeiro, 2014.

Esta revisão teve como objetivo demonstrar a importância da valina, isoleucina e leucina na nutrição de aves, destacando o metabolismo desses aminoácidos, suas funções e exigências para frangos de corte e poedeiras.

\section{2 - Proteína ideal}

O conceito de proteína ideal foi definido por Mitchell (1964) como sendo uma mistura de aminoácidos ou de proteína cuja composição atende às exigências dos animais para os processos de mantença e de crescimento. De acordo com Parsons \& Baker (1994) proteína ideal é uma mistura de aminoácidos ou de proteínas com total disponibilidade de digestão e metabolismo, capazes de atender sem excessos nem deficiências as necessidades absolutas de todos os aminoácidos requeridos para manutenção e produção da ave, para favorecer a deposição protéica com máxima eficiência.

Os aminoácidos têm funções específicas, ou seja, não são importantes apenas por fazerem parte das proteínas, e isto deve ser considerado, quando suas exigências são determinadas (Murakami, 2002). Vários trabalhos recentes obtidos de genéticas modernas mostraram a importância de providenciar níveis adequados dos diferentes aminoácidos. O aumento da exigência de aminoácidos em frangos de corte é sustentado pela evolução genética dos animais, pela disponibilidade de informação científica e pela definição dos requerimentos especificada para cada parâmetro produtivo.

A dieta pode fornecer aos animais tanto os aminoácidos essenciais como os não essenciais, os aminoácidos não essenciais nos monogástricos são sintetizados no organismo a partir de metabólitos intermediários ou de aminoácidos essenciais como, cistina, metionina, tirosina e fenilalanina, mas os essenciais não podem ser sintetizados pelo organismo numa proporção suficiente, assim, os mesmos devem ser incorporados às dietas. 
SCOTTÁ, B.A. et al. Valina, isoleucina e leucina para aves. PUBVET, Londrina, V. 8, N. 1, Ed. 250, Art. 1652, Janeiro, 2014.

Dietas deficientes em um ou vários aminoácidos essenciais impedem o crescimento normal além de poder levar a doenças e até a morte dos frangos. Dependendo do estado fisiológico, da fase e da espécie animal um aminoácido não essencial pode ser utilizado pelo organismo mais rapidamente do que é produzido se tornando um aminoácido condicionalmente essencial (D'Mello, 2003).

Como proposto, os aminoácidos essenciais são expressos em taxas ideais ou em porcentagem do aminoácido referência. A lisina, embora seja o segundo aminoácido limitante para aves, foi estabelecida como referência para as exigências dos outros aminoácidos essenciais por possuir as seguintes características: é um aminoácido estritamente essencial, não havendo nenhuma via de síntese endógena, possui metabolismo orientado principalmente para deposição de proteína corporal, a sua análise nos alimentos está em contínuo avanço, existe muita informação sobre sua concentração e digestibilidade nos alimentos, existe grande quantidade de pesquisas e informações sobre os requisitos de lisina para aves frente a uma variedade de dietas, condições ambientais e composição corporal.

A maior vantagem na utilização do conceito de proteína ideal é que esta simplifica a formulação da ração. Uma vez determinada à exigência do animal em lisina, as exigências de todos os outros aminoácidos essenciais podem ser facilmente calculadas. $\mathrm{O}$ uso da proteína ideal também facilita contornar outros fatores que influenciam as exigências dos animais em aminoácidos, tais como a densidade energética, nível protéico e potencial genético do animal para ganho em carne magra (Parsons \& Baker, 1994).

Melhores resultados ao se usar o conceito da proteína ideal são observados quando as dietas são formuladas com base em aminoácidos digestíveis, principalmente quando é utilizado grande quantidade de ingredientes alternativos e/ou de subprodutos de origem animal. Salvador et al. (2003) avaliaram o uso do conceito de proteína ideal em dietas com alimentos alternativos formuladas com aminoácidos totais ou aminoácidos digestíveis para frangos de corte nas fases de 1 a 7, 1 a 14 e 1 a 21 dias de 
SCOTTÁ, B.A. et al. Valina, isoleucina e leucina para aves. PUBVET, Londrina, V. 8, N. 1, Ed. 250, Art. 1652, Janeiro, 2014.

idade. Os autores observaram que no período de 1 a 14 dias de idade, a conversão alimentar foi pior para as aves recebendo rações formuladas para atender as exigências em aminoácidos totais.

Em experimento semelhante, Borges et al. (2003) avaliaram a utilização de ingredientes alternativos para frangos em rações formuladas com base no conceito de proteína ideal. Os autores observaram que a formulação de dietas com aminoácidos digestíveis resultou em maior ganho e melhor conversão alimentar de 1 a 7 dias, bem como de 1 a 21 dias de idade.

É importante salientar que a proteína ideal não é estática, a exigência dos aminoácidos pode ser afetada por diversos fatores como idade, níveis de PB e energia, presença de inibidores de protease, densidade populacional, estresse por calor ou frio, composição corporal, sanidade, entre outros (Holsheimer et al., 1994). No caso da temperatura ambiental, sua variação não aumenta nem diminui as exigências em aminoácidos, mas, quando o consumo da ração é alterado pela temperatura, é necessário também um ajuste em todos os nutrientes das rações. Portanto, como a proteína ideal é dinâmica, deve-se levar em consideração ao formular dietas alterações na exigência de lisina e nas relações entre os aminoácidos com a lisina.

As exigências em aminoácidos devem ser cuidadosamente estimadas, pois há a possibilidade de ocorrer certos antagonismos entre aminoácidos, principalmente se o aminoácido antagônico estiver em excesso. Por exemplo, a leucina possui antagonismo com a isoleucina e a valina, pois os três aminoácidos possuem uma cadeia longa, ramificada e similar, competindo pelo mesmo sistema de transporte através das membranas celulares e usando os mesmos complexos enzimáticos para degradação (Peganova \& Eder, 2003).

Além disso, estes mesmos aminoácidos competem com o triptofano pelo transporte através da barreira hemato-encefálica, afetando a produção de serotonina, que é um neurotransmissor com função atuante principalmente sobre o comportamento do consumo dos animais (Peganova \& Eder, 2003). Estudos em frangos de corte têm demonstrado que o excesso de valina, 
SCOTTÁ, B.A. et al. Valina, isoleucina e leucina para aves. PUBVET, Londrina, V. 8, N. 1, Ed. 250, Art. 1652, Janeiro, 2014.

isoleucina e leucina estão associados à baixa produção de serotonina no cérebro (Harrison \& D'Mello, 1986).

\section{3 - Redução do nível de proteína bruta}

A suplementação com aminoácidos industriais, principalmente metionina e lisina tem sido comum, permitindo considerável redução no nível de proteína bruta das dietas. De acordo com Le Tutour (1994), uma dieta com baixa proteína bruta pode proporcionar melhor desempenho que dietas com alto teor de proteína, que podem conter excesso de aminoácidos a serem catabolizados, levando a um maior gasto energético.

Conforme a proteína dietética é reduzida com a introdução dos aminoácidos industriais, o ajuste fino da ótima relação ideal dos aminoácidos se torna cada vez mais importante. A ordem de limitação dos aminoácidos nas dietas específicas é que determinarão quais são os aminoácidos industriais necessários a serem adicionados, para manter o ótimo balanço dos aminoácidos essenciais. Para as aves em dietas a base de milho/sorgo e farelo de soja tem-se a metionina como primeiro aminoácido limitante, a lisina e a treonina, como segundo e terceiro limitantes respectivamente (Kidd et al., 1996).

Pesquisas sobre a redução do teor de PB e a suplementação de aminoácidos industriais em rações para frangos de corte têm indicado diminuição no ganho de peso, piora na conversão alimentar e aumento na quantidade de gordura abdominal (Sabino et al., 2004). Entretanto, Rostagno et al. (2002) concluíram que é possível reduzir para 19\% o nível de PB das rações para frangos de corte de 8 a 21 dias de idade, desde que haja suplementação de aminoácidos e que o balanço eletrolítico se encontre entre 173 e 223 meq/kg. Esses autores avaliaram o efeito do nível de PB e da suplementação dos aminoácidos (arginina, glicina, ácido glutâmico, valina e isoleucina) sobre o desempenho produtivo de pintos de corte de 8 a 21 dias de idade e constataram que a redução da PB para $18 \%$ piorou o desempenho e 
SCOTTÁ, B.A. et al. Valina, isoleucina e leucina para aves. PUBVET, Londrina, V. 8, N. 1, Ed. 250, Art. 1652, Janeiro, 2014.

que as rações contendo $19 \%$ de PB necessitam ser suplementadas com glicina para proporcionar desempenho semelhante ao obtido com a ração controle (22\% de PB).

Segundo Waldroup (2000), a não obtenção de um ótimo desempenho pelas aves que consomem dietas com níveis de PB reduzidos tem sido atribuída a fatores como: níveis reduzidos de potássio e/ou balanço iônico alterado, em decorrência da redução na quantidade de farelo de soja nessas dietas, visto que esse alimento constitui a principal fonte de potássio nas rações, uma possível falta de nitrogênio para realizar a síntese de aminoácidos não-essenciais, desbalanço entre determinados aminoácidos como arginina:lisina ou aminoácidos de cadeia ramificada (valina, leucina e isoleucina), possíveis níveis tóxicos de certos aminoácidos e relação inadequada de triptofano e outros aminoácidos neutros (isoleucina, valina, leucina, fenilalanina e tirosina), que podem inibir a ingestão de alimentos pelos animais alimentados com dietas com nível reduzido de PB, pois o triptofano é precursor de serotonina, um neurotransmissor envolvido na regulação do consumo de alimentos.

Zaviezo et al. (2000) cita que em dietas comerciais para frangos de corte, é possível trabalhar com níveis mínimos de proteína bruta de $21 \%$, 18$19 \%$ e $16-17 \%$, nas fases de 1 a 21 dias, 22 a 42 dias e 43 a 56 dias, respectivamente, desde que haja a suplementação correta de metionina, lisina e treonina.

Rodrigues (2006) observou ser possível reduzir o teor de proteína da dieta de frangos de corte, no período de 21 a 42 dias de idade, sem afetar o desempenho e rendimento de carcaça das aves, bem como o teor de gordura abdominal. O mesmo autor observou que a redução no teor de PB da dieta até o nível de 18,5\%, para aves na fase de crescimento (1 a 21 dias de idade) possibilitou uma redução no nitrogênio excretado em aproximadamente $24 \%$. 
SCOTTÁ, B.A. et al. Valina, isoleucina e leucina para aves. PUBVET, Londrina, V. 8, N. 1, Ed. 250, Art. 1652, Janeiro, 2014.

\section{4 - Biossíntese e metabolismos dos aminoácidos alifáticos}

Os aminoácidos alifáticos recebem esse nome, pois possuem cadeias laterais alifáticas, e apresentam características hidrofóbicas. Nas proteínas globulares os resíduos hidrofóbicos se localizam no interior da proteína, enquanto os resíduos polares ou carregados se situam na superfície da proteína. Essa hidrofobicidade é um fator muito importante para a estabilidade das proteínas. Os aminoácidos alifáticos são a valina, isoleucina, leucina, alanina e glicina, sendo a valina, isoleucina e leucina considerados aminoácidos essenciais e de cadeia ramificada.

Todos os aminoácidos são derivados de intermediários da glicólise, do ciclo do ácido cítrico ou das vias das pentoses-fosfato, e o nitrogênio entra nessas vias através do glutamato. Há uma grande variação no nível de complexidade das vias, sendo que alguns aminoácidos estão a apenas alguns passos enzimáticos dos seus precursores e para outros as vias são complexas, como no caso dos aminoácidos aromáticos.

A valina e a isoleucina são sintetizadas a partir do mesmo precursor, o piruvato, este numa reação dependente de tiamina pirofosfato (TTP) e catalisada pelas enzimas piruvato descarboxilase e por uma transcetolase, que dão origem ao hidroxietil-TTP. Deste ponto em diante, dependendo do composto com que o hidroxietil-TTP se condensar, haverá a formação da valina ou da isoleucina. Quando o hidroxietil-TTP se condensa com outra molécula de piruvato formando o acetolactato a via é dirigida para a síntese de valina. Mas se o hidroxietil se condensar com o cetobutirato a via é desviada para a síntese de isoleucina.

A leucina é formada a partir de um intermediário da via da valina, o cetoisovalerato. O cetoisovalerato se condensa com a acetil-CoA formando o isopropilmalato, que dirige a via para a síntese de leucina.

Quanto à questão metabólica os aminoácidos podem ser classificados em glicogênicos, cetogênicos ou ambos. Os glicogênicos são aqueles aminoácidos cujo catabolismo produz piruvato ou um dos intermediários do ciclo de Krebs, 
SCOTTÁ, B.A. et al. Valina, isoleucina e leucina para aves. PUBVET, Londrina, V. 8, N. 1, Ed. 250, Art. 1652, Janeiro, 2014.

esses intermediários são substratos para a gliconeogênese e podem, portanto, originar a formação liquida de glicose ou de glicogênio no fígado e/ou músculo, os aminoácidos glicogênicos são: alanina, arginina, asparagina, aspartato, cisteína, glutamato, glicina, histidina, prolina, serina, metionina, treonina e valina.

Já os cetogênicos são os aminoácidos cujo catabolismo produz acetoacetato ou um de seus precursores (acetil-CoA ou acetoacetil-CoA), seus esqueletos de carbono não são substratos para a gliconeogênese e para a síntese de glicogênio. Os únicos aminoácidos exclusivamente cetogênicos são a lisina e a leucina. Temos ainda os aminoácidos que podem ser tanto glicogênicos como cetogênicos, como é o caso da tirosina, fenilalanina, isoleucina e triptofano.

A degradação de aminoácidos envolve dois processos: a transaminação e a desaminação. A transaminação consiste na transferência do grupo amino para o a-cetoglutarato, formando assim o glutamato e a cadeia carbônica vai ser convertida ao seu respectivo a-cetoácido. Essas reações são catalisadas por transaminases, também chamadas de aminotransferases, que são encontradas no citossol e na mitocôndria. O glutamato é, portanto, um produto comum às reações de transaminação, constituindo assim um reservatório temporário de grupos amino, provenientes de diferentes aminoácidos.

A desaminação é o processo pelo qual o aminoácido libera o seu grupo amino na forma de amônia e se transforma em um cetoácido correspondente. Esta reação é catalisada pelas enzimas genericamente denominadas desaminises ou desidrogenases que possuem como coenzimas o NADP (derivado da vitamina B3), este processo ocorre na mitocôndria hepática ou muscular.

A valina, isoleucina e leucina são metabolizadas exclusivamente no músculo, uma vez que a aminotransferase para esses aminoácidos não está presente no fígado, apenas no músculo. O metabolismo de leucina envolve sua conversão em ácido acetoacético e ácido acético através do isovaleril-CoA por desaminação e descarboxilação, sendo, portanto, um aminoácido cetogênico. 
SCOTTÁ, B.A. et al. Valina, isoleucina e leucina para aves. PUBVET, Londrina, V. 8, N. 1, Ed. 250, Art. 1652, Janeiro, 2014.

A isoleucina é convertida em isobutil-CoA por desaminação e descarboxilação, no final da via são formados o propionil-CoA e acetil-CoA sendo, esta tanto glicogênica quanto cetogênica. E a valina é convertida em isobutil-CoA por desaminação e descarboxilação e em ácido propiônico por oxidação do grupo metil e descarboxilação, sendo classificada como um aminoácido glicogênico.

\section{5 - Valina}

A valina é um aminoácido alifático similar à leucina e à isoleucina em estrutura e função. Estes aminoácidos são muito hidrofóbicos e se encontram quase sempre no interior das proteínas. As fontes importantes de valina são a farinha de soja, pescados e carnes. Ela se incorpora às proteínas e às enzimas em um índice molar de 6,9\% quando se compara com os outros aminoácidos.

A valina é um aminoácido essencial, considerada o quarto aminoácido limitante quando se utiliza o milho e o farelo de soja para compor a proteína da dieta (Kidd \& Hackenhaar, 2006). Essa limitação é mais evidente em idades maiores, quando a proteína da dieta diminui.

Dietas inadequadas em valina para aves não só reduzem o ganho de peso e pioram a conversão alimentar, como também determinaram anormalidades das pernas e empenamento (Farran \& Thomas, 1992). Leclercq (1998) também observou redução no desempenho de frangos de corte alimentados com dietas deficientes em valina, mas não mencionou efeito sobre empenamento e problemas de pernas.

Comparativamente à lisina, existem poucos trabalhos na literatura sobre as exigências de valina ou relação valina/lisina para frangos de corte. Segundo o NRC (1994), a exigência de valina total para frangos de corte machos no período de 22 a 42 dias de idade é de 0,82\%.

Corzo et al. (2004a) em experimento com frangos de corte machos dos 42 aos 56 dias de idade concluíram como melhor nível de valina digestível o de 
SCOTTÁ, B.A. et al. Valina, isoleucina e leucina para aves. PUBVET, Londrina, V. 8, N. 1, Ed. 250, Art. 1652, Janeiro, 2014.

$0,67 \%$ na dieta, uma vez que os animais apresentaram melhor desempenho, rendimento de carcaça e qualidade da carne.

Segundo Rostagno et. al (2011) as recomendações de relação valina/lisina digestível para frangos de corte na fase inicial ( 1 a 21 dias) e final (22 a 42 dias) são 77\% e 79\% respectivamente. Para a fase inicial ( 1 a 7 dias) recomendaram $1,02 \%$ de valina digestível, crescimento (8 a 21 dias) 0,937\% e terminação (22 a 33 e 34 a 42 dias) 0,882 e 0,827\% respectivamente de valina digestível.

Corzo et al. (2007), avaliaram relações valina/lisina digestível para frangos de corte machos, dos 21 aos 42 dias de idade, com dietas baseadas somente em produtos de origem vegetal e concluíram como melhor relação $78 \%$. Corzo et al. (2008) avaliaram o efeito de diferentes níveis de valina para frangos de corte machos, e recomendaram os níveis de $0,91 \%, 0,86 \%$ e $0,778 \%$ de valina digestível na fase inicial ( 0 a 14 dias), crescimento (14 a 28 dias) e terminação (28 a 42 dias), respectivamente.

Potença et al. (2009) avaliaram diferentes relações valina/lisina digestível (66, 70, 74, 78 e 82\%) para frangos de corte na fase final (28 a 42 dias) e ao contrario da maioria dos resultados observados na literatura, não observaram efeito significativo das diferentes relações no desempenho animal, contudo observaram aumento linear no rendimento de coxa e empenamento, e menor rendimento de peito com o aumento das relações. Campos et al. (2009a) concluíram como melhor relação valina/lisina digestível na fase inicial ( 7 a 21 dias) $78 \%$, e na fase final ( 28 a 40 dias) $79 \%$.

Harms \& RusselL (2001) trabalhando com poedeiras Hy-Line W36 no período de 41 a 47 semanas de idade, constataram a exigência de 592 mg, $677 \mathrm{mg}$ e $619 \mathrm{mg} /$ dia de valina para produção de ovos, peso do ovo e conteúdo do ovo, respectivamente.

Rostagno et al. (2011) recomendam um consumo diário de valina digestível de 0,699 $\mathrm{g} /$ dia para poedeiras leves $(1,6 \mathrm{~kg})$, e para poedeiras semipesadas $(1,8 \mathrm{~kg})$ 0,735 g/dia de valina digestível. E relação valina/lisina digestível para poedeiras leves e semipesadas de $95 \%$. 
SCOTTÁ, B.A. et al. Valina, isoleucina e leucina para aves. PUBVET, Londrina, V. 8, N. 1, Ed. 250, Art. 1652, Janeiro, 2014.

Lesson \& Summers (2005), trabalhando com poedeiras comerciais no período de 32 a 45 semanas de idade, recomendaram a relação valina/lisina total de $89 \%$. Bregendahl et al. (2008) trabalhando com poedeiras Hy-Line W36, de 28 a 36 semanas de idade, e utilizando como parâmetro a massa de ovo, concluíram que o aporte diário de valina digestível necessário foi de 501 $\mathrm{mg} /$ ave/dia, e a relação de valina/lisina digestível de $93 \%$.

\section{6 - Isoleucina}

A isoleucina é um membro da família alifática de aminoácidos hidrofóbicos que se encontram principalmente no interior de proteínas e enzimas. A quantidade de isoleucina em grãos de cereais (milho, sorgo e trigo) e farelo de soja, quando misturados à dieta de frangos de corte indicam que pode ser o quarto aminoácido limitante depois da treonina (Kidd et al., 2004).

Mas quando comparada com a valina, a isoleucina é menos limitante em dietas baixas em proteína bruta a base de milho e farelo de soja (Fernandez et al., 1994). Ela também é potencialmente limitante em dietas para poedeiras com baixa proteína bruta e suplementadas com lisina, metionina e triptofano.

Segundo Farran \& Thomas (1990) o requerimento de isoleucina para frangos de corte (1 a 21 dias de idade) foi 0,80\% na dieta. O NRC (1994) recomenda o nível de $0,73 \%$ de isoleucina em ração para frangos de corte no período de 22 a 42 dias de idade. Corzo et al. (2004b) recomendam o nível de $0,66 \%$ de isoleucina digestível para a fase de 20 a 40 dias de idade. As relações ideais isoleucina/lisina digestíveis estabelecidas por Baker et al. (2002) na fase de 20 a 40 dias de idade foi de $61 \%$.

Kidd et al. (2004), conduziram experimentos para mensurar os requerimentos de isoleucina para frangos de corte machos de 18 a 30, 30 a 42 e 42 a 56 dias de idade, com dietas deficientes em isoleucina e observaram que as aves tiveram redução no ganho de peso, piores conversões alimentares e menor rendimento de carcaça. As recomendações de isoleucina para o período de 30 a 42 dias de idade variaram de 0,64 a 0,66 \% na dieta. 
SCOTTÁ, B.A. et al. Valina, isoleucina e leucina para aves. PUBVET, Londrina, V. 8, N. 1, Ed. 250, Art. 1652, Janeiro, 2014.

Hale et al. (2004) realizaram dois experimentos para avaliar os requerimentos de isoleucina para frangos de corte fêmeas na fase de 30 a 42 dias de idade, e encontraram respostas quadráticas para ganho de peso $(0,67 \%)$, consumo de ração $(0,66 \%)$, conversão alimentar $(0,68 \%)$ e rendimento de carne de peito $(0,63 \%)$. Os requerimentos para isoleucina encontrados para a fase de 30 a 42 dias de idade foram entre 0,63 e 0,68\% da dieta $(0,59$ a $0,64 \%$ de isoleucina digestível).

Campos et al. (2009b) concluíram como melhor relação isoleucina/lisina digestível para frangos de corte na fase inicial e final $65 \%$ e $67 \%$ respectivamente. Rostagno et al. (2011) recomenda para frangos de corte relação isoleucina/lisina digestível de $67 \%$ para a fase pré inicial e inicial ( 1 a 21 dias) e $68 \%$ para a fase de crescimento e terminação (22 a 56 dias). E recomenda também para a fase de 1 a 7 dias de 0,887\%, 8 a 21 dias 0,816\%, 22 a 33 dias $0,769 \%$ e 34 a 42 dias $0,721 \%$ de isoleucina.

Para poedeiras leves e semipesadas Rostagno et al. (2011) recomendam relação isoleucina/lisina digestível de $76 \%$ e consumo de 0,559 $\mathrm{g} / \mathrm{dia}$ de isoleucina para poedeiras leves $(1,6 \mathrm{~kg})$ e $0,588 \mathrm{~g} / \mathrm{dia}$ para poedeiras semipesadas.

\section{7 - Leucina}

A leucina assim como a valina e a isoleucina é um aminoácido alifático, e como todos os aminoácidos sua principal função é servir de substrato para a síntese protéica, mas ela também atua como um sinal de nutrientes que regula a síntese e inibe a degradação protéica em diversos tecidos do corpo, entre eles o músculo esquelético (Escobar et al. 2005) e aumenta a atividade de proteínas envolvidas na tradução de mRNA (Wu et al. 2010).

Um dos principais objetivos da produção de animais domésticos é o de melhorar o crescimento dos animais por meio de aumento da massa muscular. Assim, a consideração da leucina na nutrição animal é 
SCOTTÁ, B.A. et al. Valina, isoleucina e leucina para aves. PUBVET, Londrina, V. 8, N. 1, Ed. 250, Art. 1652, Janeiro, 2014.

particularmente importante devido ao seu papel na regulação da síntese de proteína muscular.

Segundo Leclecq (1998) as necessidades de leucina, histidina e aminoácidos aromáticos, que são tidos como aminoácidos essenciais, não podem ser facilmente determinadas, porque eles são abundantes em alimentos e, portanto, não é fácil induzir uma deficiência drástica desses aminoácidos na dieta. Além disso, como observado no trabalho de Balbino (2008) as formulações de dietas experimentais podem levantar duvidas quanto aos resultados de exigência obtidos em experimentos, não só pela dificuldade de atender as exigências dos aminoácidos essenciais com alterações nos níveis de lisina avaliados e a redução da proteína bruta, mas também pelas poucas informações existentes sobre as exigências de aminoácidos não essenciais.

Farram \& Thomas (1990) avaliaram a exigência de leucina, isoleucina e valina para frangos de corte durante a fase inicial e recomendaram, 1,16\%, $0,80 \%$ e $0,90 \%$ de leucina, isoleucina e valina respectivamente.

Para frangos de corte Rostagno et al. (2011) recomenda relação leucina/lisina digestível de $107 \%$ para a fase pré inicial e inicial e $108 \%$ para as fases de crescimento e terminação. E para poedeiras leves e semipesadas, recomenda a relação $122 \%$ leucina/lisina digestível.

\section{8 - Conclusão}

Os aminoácidos alifáticos por serem essenciais para as aves em todas as suas fases de vida devem ser estudados para que se atendam as suas exigências para a criação de frangos de corte e poedeiras e também suas exigências para cada fase de vida, assim como suas relações com a lisina, evitando excesso de aminoácidos e o antagonismo entre os mesmo. 


\section{9 - Referências Bibliográficas}

BAKER, D.H.; HAN, Y. Ideal amino acid profile for chicks during the first three weeks posthatching. Poultry Science, v.73, p.1441-1447, 1994.

BAKER, D. H.; BATAL, A. B.; PARR T. M. et al. Ideal Ratio (Relative to Lysine) of Tryptophan, Threonine, Isoleucine, and Valine for Chicks During the Second and Third Weeks Posthatch. Poultry Science, v. 81, p.485-494, 2002.

BALBINO, E.M. Níveis de lisina digestível em rações suplementadas ou não com aminoácidos industriais para frangos de corte mantidos em diferentes ambientes térmicos. 2008. 82f. Dissertação (Mestrado em Zootecnia) - Universidade Federal de Viçosa, Viçosa, MG, 2008.

BORGES, F.M.O.; ROSTAGNO, H.S.; SAAD, C.E.P., et al. Avaliação dos coeficientes de digestibilidade dos aminoácidos do grão de trigo e seus subprodutos para frangos de corte utilizando diferentes metodologias. Arq. Bras. Med. Vet. Zootec. v. 55, n. 6, p. 722-733, 2003.

BREGENDAHL, K., ROBERTS, S.A.; KERR, B.; et al. Ideal ratios of isoleucine, methionine, methionine plus cystine, threonine, tryptophan, and valine relative to lysine for white leghorn-type laying hens of twenty-eight to thirty-four weeks of age. Poult. Sci. v. 87, p. 744-758. 2008.

CAMPOS, A.M.A.; NOGUEIRA, E.T.; ALBINO, L.F.T. et al. Digestible valine:lysine rations for broiler during the starter and finisher periods. IN: ANNUAL MEETING, POULTRY SCIENCE, 2009a, North Carolina. Proceedings ... North Carolina: Poultry Science, 2009a

CAMPOS, A.M.A.; NOGUEIRA, E.T.; ALBINO, L.F.T. et al. Effects of digestible isoleucine:lysine rations on broiler performace and breast yield. IN: ANNUAL MEETING, POULTRY SCIENCE, 2009b, North Carolina. Proceedings ... North Carolina: Poultry Science, 2009b.

CORZO, A.; MORAN, E.T.; HOEHLER, D. Valine Needs of Male Broilers from 42 to 56 Days of Age. Poultry Science, v. 83, p. 946-951. 2004a.

CORZO, A.; MORAN Jr.; E. T.; HOEHLER, D. Isoleucine need of heavy broiler males. Archiv Für Geflügelkunde, European Poultry Science Revue de Science Avicole Européenne, Germany, v. 68, p. 194-198, 2004b.

CORZO, A.; KIDD, M.T.; DOZIER III, W.A.; VIEIRA. S. L. Marginality and needs of dietary valine for broilers fed certain all-vegetable diet. The Journal of Applied Poultry Research, Savoy, v.16, p. 546-554, 2007.

CORZO, A.; DOZIER III, W. A.; KIDD, M.T.; HOEHLER, D. Impact of dietary isoleucina status on heavy-broiler production. International Journal of Poultry Science, Pakistan, v. 7, n. 6, p. 526-529, 2008.

D'MELLO, J.P.F. Amino acid as a multifunctional molecules. Amino acid in animal nutrition, Edinburgh, UK. p. 1-14, 2003.

DUARTE, K. F. Critérios de avaliação das exigências em treonina, triptofano, valina e isoleucina para frangos de corte de 22 a 42 dias de idade. 2009. Tese (Doutorado em Zootecnia). Universidade Estadual Paulista, Faculdade de Ciências Agrárias e Veterinária. Campus de Jaboticabal. 2009.

EMMERT, J.L.Y.; BAKER, D.H. Use of the idel protein concept for presicion formulation of amino acid levels en broiler diets. J.Appl. Poult. Res. v. 6, p. 462-470, 1997.

ESCOBAR, J.; FRANK, J.W.; SURYAWAN, A. et al. Physiological rise in plasma leucine stimulates muscle protein synthesis in neonatal pigs by enhancing translation initiation factor activation. An. J. Physiol. v. 288, p. 914-921. 2005. 
FARRAN, M. T.; THOMAS, O. P. Dietary requirements of leucine, isoleucine, and valine in male broilers during the starter period. Poultry Science, Champaing, v. 69, p.757- 762. 1990.

FARRAN, M. T.; THOMAS, O. P. Valine deficiency. 1.The effect of feeding a valinedeficient diet during the starter period on performance and feather structure of male broiler chicks. Poultry Science, Champaing, v. 71, p. 1879-1884, 1992.

FERNANDEZ, S. R.; AOYAGI, S.; HAN, Y. et al. Limiting order of amino acids in corn and soybean meal for growth of the chick. Poultry Science, Champaing, v. 73, p. 18871896, 1994.

HALE, L. L.; BARBER, S. J.; CORZO, A.; KIDD, M. T. Isoleucine needs of thirty- to fortytwoday-old female chickens:growth and carcass responses. Poultry Science, Champaing, v. 83, p. 1986-1991, 2004.

HARMS, R. H.; RUSSEL, G. B. Evaluation of Valine Requirement of the Commercial Layer using a Corn-Soybean Meal Basal Diet. Poultry Science, v. 80, p. 215-218. 2001.

HARRISON, L. M.; D'MELLO, J. P. F. 1986. Large neutral amino acids in the diet and neurotransmitter concentrations in the chick brain. Page $72 \mathrm{~A}$ in Proceedings of the Nutrition Society. Vol. 45. Cambridge University Press, Cambridge. 1986.

HOLSHEIMER J. P.; VEREIJKEN, P. F. G.; SCHUTTE, J. B. Response of broiler chicks to threonine supplemented diets to 4 weeks of age. British Poultry Science, London, v. 35, p. 551-562, 1994.

KIDD, M. T., KERR, B. J. L-Threonine for poultry: a review. Poultry Science, v. 5, p. 358-367, 1996.

KIDD, M. T.; BURNHAM, D. J.; KERR, B. J. Dietary isoleucine responses in male broiler chickens. British Poultry Science, London, v. 45, p. 67-75, 2004.

KIDD, M.T.; HACKENHAAR, L. Dietary threonine for broilers: dietary interactions and feed additive supplement use. CAB Reviews: Perspectives in Agriculture, Veterinary Science, Nutrition and Natural Resources, 1, No. 005, 6 pp. 2006.

LE TUTOUR, L. Applying the concept of ideal protein to piglet diet formulation. In: SIMPÓSIO LATINO-AMERICANO DE NUTRIÇÃO DE SUÍNOS, 1994, São Paulo. Anais... São Paulo: Colégio Brasileiro de Nutrição Animal, 1994. p.41-62.

LECLERCQ, B. Lysine: Specific effects of lysine on broiler production: comparison with threonine and valine. Poult. Sci., v. 77, p. 118-123. 1998.

LEESON, S., and SUMMERS, J.D. Commercial Poultry Production. 3 ed. University Books, Guelph, ON. 2005.

MITCHELL, H.H. En: Comparative nutrition of man and domestic animals. Academic Press, p. 567-647, 1964.

MURAKAMI, A. E. Nutrição e alimentação de codornas japonesas em postura. In: REUNIÃO ANUAL DA SOCIEDADE BRASILEIRA DE ZOOTECNIA, 39, 2002. Recife, PE. Anais... Recife, PE.: SBZ, 2002.

NATIONAL RESEARCH COUNCIL. Nutrient Requirements of Poultry. 9th rev. ed. National Academy Press, Washington, DC. 1994.

PARSONS, C. M.; BAKER, D. H. The concept and use of ideal proteins in the feeding of nonruminants. In: REUNIÃO ANUAL DA SOCIEDADE BRASILEIRA DE ZOOTECNIA, 31, Maringá. Anais... Maringá: SBZ, p. 120-128. 1994.

PEGANOVA, S.; EDER, K. Interactions of Various Supplies of Isoleucine, Valine, Leucine and Tryptophan on the Performance of Laying Hens. Poultry Science, v. 82, p.100-105. 2003. 
POTENÇA, A.; MURAKAMI, A. E.; URGNANI, F. J. et al. Valina na nutrição de frangos de corte na fase de 28 a 42 dias de idade, IN: reunião anual da sociedade brasileira de zootecnia, 2009, Maringá. Anais... Maringá: SBZ, 2009.

RODRIGUES, K.F. Relação lisina digestível:proteína bruta em dietas para frangos de corte. 2006. 123 p. Tese (Doutorado em Zootecnia) - Universidade Federal de Lavras, Lavras MG, 2006.

ROSTAGNO, H. S.; VARGAS JR, J.G.; ALBINO, L.F.T. et al. Níveis de proteína, eletrólitos e aminoácidos em rações de frangos de corte na fase inicial. In: CONFERÊNCIA APINCO DE CIÊNCIA E TECNOLOGIA AVÍCOLAS, 2002, Campinas. Anais... Campinas: Associação Brasileira de Produtores de Pinto de Corte, 2002.

ROSTAGNO, H. S., ALBINO, L. F. T., DONZELES, J. L., et.al. Tabelas Brasileiras para Aves e Suínos. - Composição de alimentos e exigências nutricionais. $1^{\text {a }}$ ed. Viçosa. MG, Brasil. 2011. 252p.

SABINO, H. F.; SAKOMURA, N. K.; NEME, R. et al. Níveis protéicos na ração de frangos de corte na fase de crescimento. Pesquisa Agropecuária Brasileira, v.39, n.5, p.407-412, 2004.

SALVADOR, D.; LAURENTIZ, A. C.; DAHLKE, F.; et al. Proteína ideal em dietas com ingredientes alternativos para frangos de corte na fase inicial. Revista Brasileira de Ciência Avícola, p. 27, (suplemento5) 2003.

WALDROUP, P.W. Nutritional approaches to minimizing nitrogen and phosphorus excretion in broilers. In: SIMPÓSIO SOBRE MANEJO E NUTRIÇÃO DE AVES E SUÍNOS, 2000, Campinas. Anais... Campinas: Colégio Brasileiro de Nutrição Animal, 2000. p.95-108.

WU, G. BAZER, F. W., BURGHARDT, R. C. et al. Impacts of amino acid nutrition on pregnancy outcome in pigs: mechanisms and implications for swine production. J. Anim. Sci. v. 88, p.195-204. 2010.

ZAVIEZO, D. Requerimientos de aminoácidos de pollos y gallinas. Avicultura Profesional, $v$. 18 , p. $18-22.2000$. 